\title{
The Position of a Teacher as a Factor of Forming Students' Socio-Cultural Identities (On the Example of the Russian Civil Identity)
}

\author{
Marina V. Shakurova ${ }^{1}$ \\ ${ }^{1}$ Voronezh State Pedagogical University, Russian Federation \\ Correspondence: Marina V. Shakurova, Voronezh State Pedagogical University, Lenina str., 86, Voronezh \\ 394043, Russian Federation.
}

Received: September 19, 2014

Accepted: October 29, 2014 Online Published: December 30, 2014

doi:10.5539/ies.v8n1p125

URL: http://dx.doi.org/10.5539/ies.v8n1p125

\begin{abstract}
The article presents experience of structuring and description of teachers' position in the process of forming socio-cultural identity of the person, detailed in regard to the process of formation of one of the subtypes of socio-cultural identity-Russian civil identity. We identified and described real subjective, nominally subjective and non-subjective positions. Based on the author's vision of the essence of socio-cultural identity of the person, its relationship to personal and ego-identity, it is argued that educational organizations, teachers can play a significant role in shaping socio-cultural identity, and development of personal identity can be effectively accompanied. As invariant characteristics defining the teacher's position as the subject of the formation of pupils' socio-cultural identity we considered: level of information skills; importance of the teacher for students and/or "support" on the other significance; taking into account personal experience of pupils, their formed attitudes and preferences, referents' influences on choices and self-determination; ability of the teacher to organize students' activities and stimulate certain attitudinal reactions; the teacher' reflection of his/her own characteristics of socio-cultural identity. For detailed descriptions, definitions of variant traits we considered the teacher's position as the subject of forming the Russian civil identity and illustrated it with the results of empirical research conducted on the basis of schools in Voronezh and the Anninskiy district of the region, Voronezh State Pedagogical University.
\end{abstract}

Keywords: identity, socio-cultural identity of a person, reference, anthropo-images and examples, the position of the teacher

\section{Introduction}

The present stage of development of scientific and pedagogical knowledge is estimated by experts as a period characterized by manifestations of a paradigm shift. A number of fundamental ideas expressed and justified by Russian researchers constitute the essence of changes that define new vectors of formulation and solution of scientific and pedagogical problems. "Shaping the research program of education identity" is among them (Methodological consequences of a paradigm shift in the theory of education, 2011).

Introducing the concept "identity", which has interdisciplinary nature and multi-level semantic content, into the pedagogy makes us not only deploy a separate line of research, but also revise the already well-established scientific-pedagogical positions. In Russian educational research of the last decade, it is obvious that attention is paid to the study of developmental processes of identity and subjectivity, self-determination, personal growth (Bratchenko, 2001; Kulikova, 2003; Nikitina, 2005; Student's personality as the goal, object, subject and the result of education, 2004), which in some cases led the authors to the need to resorting to the notion of "identity" and related concepts. The problem of identity has not been developed in the Russian pedagogy to the extent that would allow not only selecting and retaining the originality of this phenomenon in descriptions, research and practice, but also adequately accompanying the process of identity development, preparing teachers for the formation of various types of schoolchildren's identities.

\section{Methodology}

Let's illustrate this conclusion with regard to the process of formation of the Russian civil identity (hereinafter RCI) of students as socio-cultural identities. The study was conducted in 2008-2013. Such methods were used as 
interviews, questionnaires (a specially designed questionnaire), analysis of activities products (programs of academic disciplines).

The study of the teachers' position in the process of forming socio-cultural identity of the person began in 1998 . In the first period (1998-2008) as a result of a theoretical analysis of the literature, interpretation of the results of non-teaching research, modelling the structure of the person's socio-cultural identity and the process of its formation, observing professional work of teachers, their contact with students, method of focus groups with teachers and students of the Pedagogical university, necessary characteristics of the teacher's position were given, the characteristics that are important from the point of view of the formation of the person socio-cultural identity. In the second period (2008-2014) original characteristics of the position were specified in relation to the formation of separate subtypes of the socio-cultural identity, in particular - Russian civil identity. The consistency of the selected invariants was proved, developed and they passed the examination of positioning types descriptions. Such methods were used as interviews, expert evaluation, questionnaires (a specially designed questionnaire) and activities product analysis (programmes of academic disciplines). Research database: three school of Voronezh, two schools of the Anninskiy district of the Voronezh region, Voronezh State Pedagogical University.

Results of the study are summarized as follows: a description of positioning types is given, these types are compiled on the basis of invariant characteristics and are complemented with manifestations which are characteristic for the formation of the Russian civil identity as one of the types of socio-cultural identity.

Actual subject position suggests primarily defined level of information skills of the teacher. Three blocks of knowledge and understanding are mandatory: general scientific unit (knowledge about the nature of identity, the ratio of this construct and broader concepts such as self-awareness, self-concept, selfhood; types and levels of identity, common understanding of the Russian identity; manifestations of the Russian identity on the social and individual levels, etc.); informative unit (what images and patterns can be and actually are in different communities of the construct "Russian", how this set relates to the basic characteristics of such close in meaning personal qualities like "patriot", "citizen", "Russian people" and so on); procedure (the formation and development of the Russian identity at the individual and group level, the necessary conditions in this regard, peculiarities of the formation of the Russian students' identity related to age characteristics of students, as well as peculiarities of the social and cultural situation of their development, etc.).

Our pilot study (random sample; 42 teachers) allows us to give a few illustrations (Mahinin \& Shakurova, 2012). For example, in the process of interviewing teachers were requested to describe identity as a personal characteristic and formulate their own idea of RCI. All the interviewed teachers identified the need to understand and study this phenomenon ("it is discussed more and more often", "documents of education standardization don't contain this information", "civil identity is named as a goal/objective of the school in recent documents"). To characterize the identity the interviewees often used the following attributes: refers to a worldview; relates to self-understanding, identification result, i.e. imitation. Not a single teacher was able give a precise definition what identity is. The degree of adequacy of the attributes can be estimated at $30-40 \%$ of the corresponding model parameters. $58 \%$ of interviewees believe that RCI can be taught.

During the interviews with teachers and students of the Voronezh State Pedagogical University (random sample, 78 students of 2-4 courses from two departments, 26 teachers, 2014) and an analysis of programme materials, it was concluded that in psychological and pedagogical training in this particular university topics on the basics of psychological and pedagogical support of the formation of personal identity were not emphasized (usually - not included). Programmes on psychological and pedagogical disciplines do not include references to the theory of identity (with the exception of the review of Erikson's heritage).

A mandatory feature for the actual subject teacher's position is the importance of the teacher for students and/or "reliance" on the other's significance. Significance is the result of a choice. Choosing a person, a group in his/her own environment, the individual determines the priority channel for receiving information for him/her, a preferred source of experience and material for self-construction. Obviously, for a complete solution of professional problems the teacher should be significant (either personally or as a representative of the relevant group, community or as a carrier of information of interest, experience). At the same time, we should talk about full significance, based on the combination of authority, emotional appeal and power.

As a result of observing professional activities of teachers in five schools of Voronezh (3 schools) and the Anninskiy district of the Voronezh region ( 2 schools) two dominant tactics have been identified. The characteristic of the first tactic is searching for interaction channels, and the second one is based on the belief that children take from the teacher what they want to take, therefore, no special effort to keep pupils' interest on 
the teacher as a person, an information carrier and a possible example is not worth taking. For the described position, the first described tactic is characteristic. In all fairness, we emphasize that to become significant for every child is an almost impossible task. To assert "should" - means to put an obviously impracticable task before a teacher or a tutor. The teacher can and must learn to rely on significant Others of the child, in order to meet pressing educational challenges.

There may be situations when the teacher is a referent adult for students, but the images and examples proposed by him/her cause rejection, negative reaction ("we don't have anything against, but we do not support what you're talking about"). In this regard, for the actual subject position of the teacher it is important to consider the personal experience of pupils, their formed attitudes and preferences, referents' influence on choices and self-determination. The teacher should know and take into account age specifications.

Junior high school students use the brightest and the most frequently repeated specifications given by the parents, media and a primary school teacher. They are not as demanding to realism of images and patterns, as teenagers and high school students.

Teens adjust the existing structure, adding shocking and not always positive features. Members of this age group are dependent on reading the concept of "Russian" in the highlights, which is reflected on the Internet, movies, television entertainment shows.

High school students are more selective and seek to create their own structure, as a rule, from traditional characteristics. They are willing to debate and discuss the consistency of their own and other versions. It is assertion of their own structure matters to them, at the same time realism, corroborability in practice is used as the main criterion.

The teacher is to not only formulate and present a certain structure, but also to be ready to defend it in a non-declarative way. With regard to the formation of RCI as a socio-cultural identity, it may include differences in strategies and tactics in teachers' activities.

The teacher of elementary school should be clear and concise, his/her set of definitions needs to be consistent not only with the current interpretation of the marker "Russian" in school (if such happened) and with socio-state interpretation, but also to consider the most striking statements of parents and close significant surroundings of children.

The teachers of teen classes are forced to defend the positive characteristics, look for vivid confirmation of their consistency, counterarguments for negative-controversial points.

Teachers in high school cannot be limited to informing, their task is to join the discussion, to transfer the question from cognitive to activity-relational plane.

From those adults, teachers are leaders who remind high school students that they are "Russians".

Let us illustrate this statement with the results obtained in the survey of 175 students ( 35 people from an educational institution, a random sample).

The majority of respondents (68.9\%) name family members as a lead referent. At the same time, as a rule, not only one member of the family stands out, but a few, including grandparents, aunts, uncles, godparents, sisters, brothers, nephews. Only $22.1 \%$ of respondents named one or more classmates among the referents. Teachers were noted as significant persons in $8.3 \%$ of the questionnaires (in this case we have combined class teachers, subject teachers, supplementary education teachers). Only in $1.9 \%$ of the responses, $2-3$ teachers were named as significant others (usually they include the head of some extracurricular activity or a section).

The surveyed students responded to the question "How often are you reminded that you are a Russian?" as follows: often- $14.4 \%$ of respondents; sometimes $-48.1 \%$ of respondents; occasionally- $37.5 \%$ of respondents. It should be emphasized that for the formation of RCI its actualization is important as well as broadcasting the image regularly.

A student is most often reminded that he is Russian by teachers $(52.4 \%$ of respondents); media- $22.2 \%$ of respondents; parents $-20.1 \%$ of respondents; friends $-10.2 \%$ of the respondents. It is clear that at sufficiently low rates of reference, teachers continue to be the leading subject of solving the problem of the formation of RCI as a socio-cultural identity. A more significant group-friends (we assigned classmates to it) has virtually no effect on the formation of RCI as the topic of citizenship, patriotism, "being Russian" is relevant and actively discussed only in certain situations by high school students. It is not so relevant for leading referents-family of a high school student. The main "competitor" for teachers is media which has a much larger number of choices as significant, referential for students' self-determination. 
The actual subjective position of the teacher in the formation of students' RCI as socio-cultural identity as another binding characteristic involves the ability of the teacher to organize students' activities and stimulate certain attitudinal reactions. This characteristic from the perspective of educational theory seems trivial. However, the analysis of the education practice suggests that dominant methods, including in high school, are verbal ones.

For the formation of socio-cultural identity (including RCI as socio-cultural identity), all organization and activity arsenal of modern pedagogy can be used, direction plays an important role as well as relationships that are formed at the same time. There is also an important feature: the ratio should be kept and confirmed, first of all, in everyday real life in the educational organization and beyond. The priority techniques are problematization, social design, methodology of collective-creative activity, social hardening techniques, etc.

The actual subjective position of the teacher in the formation of RCI as a socio-cultural identity of students involves the ability of the teacher to work with an example, taking into account age of pupils, their cultural level. The example in this case is the realistic confirmation of consistency of proposed images and samples.

Let us refer to the illustration. The survey, the results of which have already been cited above, included the following question: "Are there people in your surrounding whose example you'd like to follow?" Respondents made the following choices: mother- $51 \%$ of the respondents; father $-29.9 \%$ of the respondents; friends $-13.5 \%$ of the respondents; I do not need examples $-12.8 \%$ of the respondents; teachers $-6.9 \%$ of the respondents; no examples $-3.1 \%$ of the respondents.

An obvious problem with images-examples is illustrated with the answers to the open-ended question: "When they say that they are real Russians, whom do you remember most often (from historical characters; from literary heroes; television and movies characters; one of your contemporaries; of those around you)?" The greatest number of options was proposed in the group "historical figures" (the most popular answers were Peter I, Russian bogatyrs, Catherine II, Ivan the Terrible). Once again, we have received confirmation of the fact that educational reality in most educational institutions is oriented on images and examples of the past. Among literary figures epic bogatyrs and heroes of fairy tales slightly dominated. Some of the respondents attributed writers and poets to this group, highlighting Alexander Pushkin and Mikhail Lermontov in particular. In the immediate surrounding members of the family, friends were predominantly named.

Teachers themselves admit that experience in using the method of example in modern educational practice is depleted. There are two apparent views consequent to this problem, which require special consideration: content (whom we can use as an example to pupils of different ages) and methodological (how to organize work with the example in changed socio-cultural environment).

We will complete identifying the characteristics with indicating the need for the teacher to reflect leading characteristics of his/her own socio-cultural identity as a whole (what communities, groups or personalities are significant for him/her; what anthropo-images he/she shares in this regard, and what images he/she is able to demonstrate) and Russian identities, in particular. It is clear that there are deep contradictions caused by, for example, the mismatch of the concept of the marker "Russian" of a particular teacher and the one generated within the formation of the identity politics of the educational institution; crisis periods in the development of the identity of the teacher; signs of hyper or hypo identity of particular teachers, etc.

Taking the highlighted characteristics of the subjective position as the basis, we will give a description of the nominal subjective position and non-subjective position.

The nominal member is a person who is determined by others as an included member into the group system of social interaction, but in fact, has stopped interacting with others in the group. Performing, sometimes quite effectively, the prescribed role, such subjects live their own interests not correlating them with the interests of those with whom they meet at school. They do not see the possibility (for various reasons) to realize these interests in school life. The nominal subjective position of the teacher in the formation of socio-cultural identity (in a particular case-the formation of RCI) is a widespread phenomenon. To all the teachers as participants in the educational process, including the process of civil and patriotic education, subjectivity is prescribed. Therefore, the subjective position in the formation of socio-cultural identity of pupils including in the formation of RCI is attributed to them. However, teachers with this position (they are the majority) do not have necessary information or it is insufficient; the significance of teachers is limited (usually the significance is on the basis of authority); personal experience of students, their formed attitudes and preferences are declared, but not really studied and taken into account in organizing interaction with them; ability to organize activities of students, stimulate certain attitudinal reactions is either not formed or preference is given to verbal methods of work; the example has been neglected since the required qualities are declared and according to features of the position do 
not require confirmation. The latter characteristic involves a large number of variants: from the problems with self-identity to unformed reflection.

The non-subjective position of the teacher is more difficult to understand and describe. It is common to oppose subjectivity to objectivity, but in our case, the teacher cannot be an object. He/she is a "non-subject". At the same time the teacher is against prescribing him/her the function of directional influence on the formation of socio-cultural identity of pupils (including RCI), stressing that "this is not the task of the school" or "school does not solve anything in this matter." We can assume that these teachers, for example, possibly have a sufficiently high level of information, they quite well realize the complexity of the implementation of the task, but do not even try to begin to deal with it. The nature of such position may be in the unformed professional identity of teachers: they do not see themselves as teachers, but formally perform official duties.

\section{Discussion}

Advisability of pedagogical problematization of the identity idea is obvious to us. By using this concept and its semantic codes, it is possible to emphasize:

$\checkmark \quad$ subjective-personal level of pedagogical phenomena analysis;

$\checkmark$ emphasize the importance of relationships (relational representations (Cervone, Caldwell, \& Orom, 2008) in the structure of activity and communication;

$\checkmark \quad$ to specify the mechanism of transition from social to individual. In particular, an additional opportunity appears to study how external influences of culture or socialization agents can affect inner experience and subjectivity of the developing person (Christopher \& Bickhard, 2007);

$\checkmark \quad$ to actively use the principles of realism, cultural, social and human congruity of socio-educational and proper pedagogical practices. According to the developer of one of the first concepts of identity Erikson (Erikson, 1996; Erikson, 2002), one of the essential characteristics of identity is its realism. When the teacher provides anthropo-images to a student, he should make sure that they do not become an alienated norm. When it comes to children and young people, these anthropo-samples should be: a) man-sized (be of a size a modern man can really be or to become); culture-sized (these anthropo-samples represent importance and value of culture in general and those sub-cultures which in most cases belong to (or may belong to) children and young people); society-sized (the modern society has the minimum required set of conditions that allow a person to self-fulfil with such characteristics); they should not be replaced by abstract descriptions or names of though desired but generalized qualities (Genisaretsky, 2001).

Together with the necessity of pedagogical context in the identity study, we should point out objective complexity of using this characteristic in education. As emphasized by Baumesister and Muraven (1996), social and cultural changes brought about by the development of society led to a significant increase in the hidden, implicit in the structure of personality. Adoption of the existence of a large and important internal "I" shaped the nature of modern identity. It is much harder to identify, examine, understand and shape the hidden self. However, the difficulty does not deny the possibility, which is more connected with the phenomenon of "generalized Other", which determines the formation of identity. In the works of Cooley (2000) it is emphasized that a person from birth does not have any system of criteria for evaluating himself/herself. An individual learns them from others and on this basis forms his/her own set of criteria and concepts. Influence from significant others increases in relation to the components of the "self-concept", for which there are no sufficient grounds for own opinions or evaluated by others with explicit unanimity. This interdependence is treated as a paradox: the individual is aware of his/her own identity only when looking at yourself through the eyes of another: it clears the view and the position of the other person in relation to us, as we use other people's point of view and positions to ourselves (Abels, 2000). The conclusion of Slavskaya is of fundamental nature: achievement of identity is not carried out only in the case of defining "I" under the allocation of its generality, but also under a change of reality, as well as developments related to the dynamics of the life journey (Slavskaya, 2005).

Taking into account different level of admissibility of pedagogical intervention into the process of formation and development of personal identity, we emphasize the need for an adequate assessment of pedagogical strategies for accompanying the formation of a social, personal and ego-identity. Teachers, school can make the best possible results in the process of forming social identity. Ego identity is practically inaccessible to direct pedagogical influence, control and correction.

Since Erikson $(1996,2002)$ wrote his textbook works (feeling of identity, identity crisis, epigenetic concept of identity), Tajfel (1982) (social identity) and Turner $(1975,1985)$ (self-categorization), there have been changes in the social context of public life, changes actualizing the cultural component. Scientific knowledge has responded 
with the active use of the construct "socio-cultural".

On the one hand, the premise was recognition of the fact that every cultural object has its social dimension (the number of people or social groups, institutions, for which it is the main source of organization and defines the meaning of everyday life), which determines the possibility and appropriateness of socio-cultural discourse. On the other hand, the growing importance of the cultural component was noted. Entrenched socio-cultural context of the analysis of the identity phenomenon, as Orlova (2002) points out, allows determining the characteristics of the cultural "design" of the method of subjective organization of events (as they are experienced, interpreted, evaluated), isolating the communication mechanisms between intrapersonal (awareness, interpretation, evaluation) and external socio-cultural (objects, symbols) conditionality of actions in all situations of social interaction. With regard to the identity theory, this transition became the basis for treating as equal processes and results of the individual's responses to social and cultural markers.

The topical research task is still to define "socio-cultural identity". Analysis of the various points of view (Ivanova, 2004; Genisaretsky, 2001; Semenenko, 2003) on the essence of the examined phenomenon suggests that the following characteristics are crucial for defining "socio-cultural identity":

$\checkmark \quad$ in the growing number of membership options the inclusion of the individual in certain social groups and communities, the awareness of belonging to a certain social institutions plays an important role;

$\checkmark$ membership may be different (from the functional to the subjective, event-driven), individual value of membership in a particular social formation becomes of key importance;

$\checkmark \quad$ the role of choice, self-determination in exhibited by different social formations cultures increases;

$\checkmark \quad$ successful adoption of cultural requirements is due to status and positional certainty in a social group or community.

We consider the socio-cultural identity as an element in the structure of self-consciousness, which is manifested in procedures of feelings, comprehension and realization of the subject of his/her certainty and continuity in the process of adoption, internalization and externalization of cultural models, broadcasted by significant from his/her point of view social institutions, communities, groups, individual actors.

The fact that the same sort of identity is formed in a dialectical relationship at three levels is fundamental to pedagogy. These three levels are socio-cultural, personal and ego-identity level. In this context, the term "socio-cultural identity" becomes a marker of one of the development levels of different identity types. Fundamentals for this level are as follows:

$\checkmark$ referents demonstrating anthropo-images and samples (e.g. for gender identity-images of men or women, for ethnic identity-a representative of the corresponding ethnic group, etc.);

$\checkmark$ adoption of these anthropo-images and samples by schoolchildren according to the mechanism of similarity, likeness;

$\checkmark \quad$ identification of students' referents in themed anthropo-images and samples.

It is obvious that one of these referents for a child can and should become a teacher-the leading subject of formation of various types of students' identities in the education system. Theoretical analysis, long-term monitoring and special studies show that in practice different levels of teachers' positioning in the process of forming socio-cultural identity of students are common. The most common levels are actual subjective, nominally subjective and non-subjective positions.

\section{Conclusions}

In this article, we examined the actual subjective, nominal subjective and non-subjective positions of the teacher in the process of forming the Russian civil identity as a form of socio-cultural identity of the person. The basis for structuring was formed from invariant characteristics for all kinds of the person's socio-cultural identity: level of information skills; importance of the teacher for students and/or "support" on the other significance; taking into account personal experience of pupils, their formed attitudes and preferences, referents' influences on choices and self-determination; ability of the teacher to organize students' activities and stimulate certain attitudinal reactions; the teacher's reflection of his/her own characteristics of the socio-cultural identity (what communities, groups or personalities are significant for him/her; what anthropo-images in this regard he/she shares, and what he/she is able to demonstrate).

Appealing to the results of empirical studies of the formation of the pupils' Russian civil identity and the teacher's position in this process allowed us to detail description of the actual subjective position as the best one 
to meet challenges of forming RCI. In particular, ignorance of the essence of the personal identity and the formation of socio-cultural identity characteristics plays a negative role for the real subjective position development, as well as lack of understanding of the teacher's opportunities and his/her role in this process, teachers' low reference indexes for pupils, lack of attention to this issue, including the teachers themselves, blurred images-examples, which are necessary for the formation of identity.

Obviously, the characteristics selected for structuring should be purposefully supported by the system of vocational education and the teacher himself/herself. The following factors can contribute to it:

$\checkmark$ address training of future teachers in institutions of higher education, further improvement of information skills and methodological literacy of already working teachers, including themed teachers training (taking into account a type and a level of the formed identity);

$\checkmark$ deliberate teachers' work aimed at strengthening their own significance in all-school communities, in communicating with certain students;

$\checkmark \quad$ forming the teacher's ability to diagnose and build productive relationships with significant for students people, groups, communities;

$\checkmark$ reflection by the teacher of his/her own activity, methodological literacy, professional and personal position.

These and others ways of providing the actual subjective position for the teacher in the process of forming students' socio-cultural identities, as well as ways and methods of preventing and correcting the nominal subjective and non-subjective positions of teachers need further comprehension and experimental studying.

The article is prepared within the framework of the state task \#2014/310 to implement state work in science as a part of the basic part of the state task of the Ministry of Education and Science of Russia for the project "Training of a student in pedagogical institutions of higher learning to form schoolchildren's socio-cultural identities.

\section{References}

Abels, H. (2000). Interaction, identity, presentation. Introduction to interpretive sociology. Saint Petersburg: Aletheia.

Baumesister, R., \& Muraven, M. (1996). Identity as adaptation to social, cultural, and historical context. Journal of Adolescence, 19, 405-416.

Bratchenko, S. (2001). Humanitarian expertise in education: Criteria for personal growth. School technologies, 2, 179-195.

Cervone, D., Caldwell, T., \& Orom, H. (2008). Beyond Person and Situation Effects: Intraindividual Personality Architecture and Its Implications for the Study of Personality and Social Behavior Intraindividual. In F. Rhodewalt (Ed.), Personality and social behavior Personality and social behaviour (pp. 9-48). New York, London: Taylor \& Francis Group, LLC.

Children learn from us. (2009). The first of September, 10, 7-8.

Christopher, J., \& Bickhard, M. (2007). Culture, Self and Identity: Interactivist Contributions to a Metatheory for Culture \& Psychology. http://dx.doi.org/10.1177/1354067X07079881

Cooley, C. (2000). Human nature and social order. Moscow: Idea Press, House of intellectual books.

Erikson, E. (1996). Identity: Youth and Crisis. Moscow: Publishing Group "Progress".

Erikson, E. (2002). Childhood and Society. Saint Petersburg: LLC "Rech".

Genisaretsky, O. (2001). Cultural identity and an image of territory. Spatiality of development and metaphysics of Saratov. Saratov: Povolzhskaya AGS.

Ivanova, N. (2004). Social identity in various socio-cultural conditions. Questions of psychology, 4, 65-75.

Kulikova, L., \& Krysin, V. (2003). Methods of measuring complex pedagogical characteristics. School technologies, 6, 130-146.

Mahinin, A., \& Shakurova, M. (2012). Pedagogical conditions of formation of the Russian civil identity of senior pupils in extra-curricular activities in educational institution: a monograph. Voronezh: Voronezh State Pedagogical University.

Nikitina, N. (2005). Self-identity as a sociocultural phenomenon. New value of education, Education of "I", 2(21), 16-27. 
Orlova, E. (2002). Sociocultural space of everyday life. Moscow: Gask.

Selivanov, N., \& Sokolov, E. (2004). Personality of a student as an aim, object, subject and a result of education. Moscow-Tver: Ltd. IAP "Viart".

Selivanov, N., \& Sokolov, E. (2011). Methodological consequences of a paradigm shift in the theory of education. Moscow-Tver: Ltd. IAP "Viart".

Semenenko, I. (2003). Globalization and sociocultural dynamics: Individual, society, culture. Policy, 1, 5-23.

Slavskaya, A. (2005). Individual as a subject of interpretation. Dubna: Fenix.

Tajfel, H. (1982). Social identity and intergroup relations. P.: Maison des Sciences de 1'Homme and Cambridge: Univ. Press.

Turner, J. (1975). Social comparison and social identity: Some prospects for intergroup behavior. Europ. J. Soc. Psychol., 5, 5-34.

Turner, J. (1985). Social categorization and the self-concept: A social cognitive theory of group behavior. Advances in Group Processes, 2, 77-121.

\section{Copyrights}

Copyright for this article is retained by the author(s), with first publication rights granted to the journal.

This is an open-access article distributed under the terms and conditions of the Creative Commons Attribution license (http://creativecommons.org/licenses/by/3.0/). 